\title{
Seni Tradisi Dan Folklor Sebagai Suatu Elemen Pendukung Data Arkeologis Dalam Mencari Harijadi Sebuah Kota/ Wilayah (Studi Kasus di Pasuruan, Jawa Timur)
}

\section{Hari Lelono}

Keywords: folklore, ethnography, ethnoarchaeology, tradition, culture, arts

\section{How to Cite:}

Lelono, H. (2003). Seni Tradisi Dan Folklor Sebagai Suatu Elemen Pendukung Data Arkeologis Dalam Mencari Harijadi Sebuah Kota/ Wilayah (Studi Kasus di Pasuruan, Jawa Timur). Berkala Arkeologi, 23(2), 127-137. https://doi.org/10.30883/jba.v23i2.881

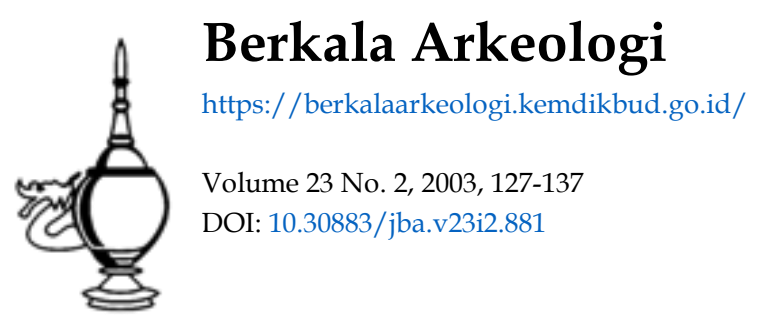

\section{(1)@(2)}

This work is licensed under a Creative Commons Attribution-NonCommercial-ShareAlike 4. 0 International License. 


\title{
SENI TRADISI DAN FOLKLOR SEBAGAI SUATU ELEMEN PENDUKUNG DATA ARKEOLOGIS DALAM MENCARI HARIJADI SEBUAH KOTA / WILAYAH. (Studi Kasus di Pasuruan, Jawa Timur)
}

\author{
T.M. Hari Lelono
}

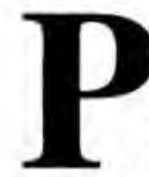

\section{endahuluan}

Mencari harijadi sebuah daerah (kabupaten, kota) merupakan tugas gampangcukup banyak dan mudah ditelaah, Sulit apabila sumber sejarah tersebut sangat sedikit, samar-samar dan kurang jelas. Memang terbentuknya atau lahirnya sebuah regentschap (bestuur van regent) atau gemeente (onderdeel van de sataat) pada jaman penjajahan Belanda mudah dicari berdasarkan data kolonial yang tersimpan di Jakarta (Arsip Nasional) dan Deen Haag, Belanda. Menurut hemat kami mencari harijadi ditelusuri berdasarkan data tertua (prasasti dan naskah) yang menyebut tempat, pemukiman (settlement), sima atau daerah perdikan (misalnya sima Mantyasih yang menjadi Mateseh di kota Magelang). (Atmodjo Sukarto, 1996).

Dari pandangan yang paling tertua data yang dipakai berupa data-data arkeologis yang ada dapat pula diacu dari cerita-cerita rakyat yang ada dan beberapa tradisi masyarakat, Dalam konteks ini dicari kaitan/ benang merah antara data kuno dan data tutur, tradisi yang ada didaerah tersebut, sehingga diharapkan dapat tersusun lengkap tentang sejarah lokal yang terjadi di daerah bersangkutan.

Kebudayaan adalah rasa, karsa dan hasil cipta karya manusia yang paling tinggi nilainya, semakin tinggi dan majemuknya hasil karya ciptaan manusia tersebut menandakan semakin tinggi peradaban yang dimilikinya. Oleh karena itu generasi yang ada pada saat ini wajib untuk melestarikan dan bahkan mengembangkan warisan budaya yang telah diciptakan leluhur bangsa kita untuk kemajuan dan bersaing secara kompetitif dengan kebudayaan lain, mungkin terdapat perbedaan-perbedan dan persamaan-persamaan untuk saling mengisi memajukan guna memperkaya kebudayaan itu sendiri. Tentunya dalam mempekaya unsur-unsur budaya tersebut dapat dipilih hal-hal yang baik (positif), sedangkan hal-hal yang kurang sesuai dengan nilai-nilai dalam budaya kita disingkirkan.

Suatu kelompok atau masyarakat yang tinggal dalam suatu wilayah tertentu pastilah memiliki seni dan tradisi yang merupakan warisan dari generasi sebelumnya. Seni muncul sebagai akibat kerinduaan manusia akan rasa keindahan yang abstrak kemudian diwujudkan dalam bentuk yang nyata berupa misalnya; seni pertunjukan, seni suara dan seni lukis. Dari sekurangnya tiga unsur seni tersebut hampir disetiap 
masyarakat secara umum berkembang dengan baik. Salah satunya adalah seni pertunjukan yang merupakan gabungan dari seni gerak/ tari/suara dan didukung oleh separangkat alat bunyi berupa gamelan (Jawa) dan tabuhan-tabuhan tertentu. Pertunjukan yang dipentaskan tersebut biasanya muncul dengan mengambil lakon atau cerita yang ada didaerah tersebut. Cerita yang diangkat sebagai seni tersebut biasanya sudah dikenal secara luas dengan nama cerita rakyat (folklore). Cerita rakyat tersebut biasanya mengandung pesan-pesan seperti; epos/ kepahlawanan, asal-usul nama atau suatu daerah, nilai-nilai penting yang perlu dihayati oleh masyarakat (pesan-pesan moral), dan cerita jenaka yang disukai masyarakatnya.

\section{Cerita Rakyat/ Tutur}

Mengenai cerita rakyat yang hampir dimiliki oleh setiap suku, kelompok masyarakat tersebut banyak ahli mengemukan berbagai batasan tentang cerita rakyat (foklore), diantara mereka salah satu yang menarik adalah Jonas Balys, mengatakan bahwa: Folklor menampung kreasi-kreasi masyarakat, baik yang primitif maupun moderen. Dengan menggunakan bunyi dan kata-kata dalam bentuk puisi dan prosa, meliputi juga kepercayaan dan ketakhayulan, adat kebiasaan serta pertunjukan, tari-tarian dan drama-drama rakyat (Leach 1949).

Dalam berbagai kelompok masyarakat pedesaan Jawa, mereka mengenal cerita rakyat yang biasa dikaitkan dengan keberadan suatu tempat/ situs dan tokoh tertentu yang dikaitkan dengan latar agama, kepercayan, dan kehidupan sosial, ekonomi politik daerah tersebut. Cerita tersebut berkembang dan sering dituturkan kepada generasi berikutnya sebagai contoh-contoh ketoladanan dan pendidikan yang penting agar menghormati tatanan dan lingkungan alam sekitar tempat tinggalnya. Dari bermacam cerita rakyat tersebut yang dianggap bisa menimbulkan rasa bangga dan membangkitkan harga diri bagi daerahnya sering pula di pertunjukkan dalam kesenian seperti ketoprak, dan drama tari tertentu.

Folklor dapat dikatakan sebagai ekspresi yang nyata dan langsung dari alam pikiran masyarakat. Folklor mengekalkan pola-pola kebudayaan suatu kelompok masyarakat dan dengan mempelajari folklor kita dapat m,enerangkan motif-motif adan arti kebudayaan mereka. Dengan demikian ilmu folklor memberikan banyak sumbangan terhadap kehidupan suatu masyarakat, sejarahnya dan interpretasi dari kehidupannya (Leach 1949).

\section{Data Arkeologis Sekitar Pasuruan}

Sumber data arkeologis dapat diacu sebagai salah satu bukti sejarahan bahwa di daerah/ wilayah bersangkutan pernah hidup dan berkembang suatu peradaban manusia. Bukti-bukti tersebut sangat penting dalam usaha untuk menelusur dan 
mencari harijadi sebuah kota/ kabupaten. Beberapa tinggalan arkeologis di daerah tersebut adalah: ${ }^{1}$

Tinggalan yang bermasa prasejarah( manusia belum mengenal baca tulis) dan tinggalan bermasa klasik (pada masa Hindu dan Buda)

Tinggalan Prasejarah:

\section{a. Alat Paleolitik}

Pada aliran Sungai Baung (hulu Sungai Welang) yang terletak di Desa Purwodadi, Kecamatan Purwodadi telah ditemukan sebuah alat dari tradisi paleolitik. Alat ini berupa sebuah serpih besar, dengan ukuran panjang 23,5 $\mathrm{Cm}$, lebar $12,5 \mathrm{Cm}$, dan tebal $4 \mathrm{Cm}$. Bahan alat adalah jenis andesit. Pada bagian dorsal serpih berfaset, sedang pada bagian ventral terdapat 2 pangkasan yang mengarah ke bagian tajaman. Dalam terminologi teknologi alat batu dengan pangkasan yang demikian ini disebut sebagai kapak penetak. Sementara itu pada bagian tajamannya berperimping yang menunjukkan akibat pemakaian..

\section{b. Menhir}

Di dekat mata air yang berada di Desa Betro, Kecamatan Gempol terdapat 3 menhir yang berdiri di atas tatanan batu. Ketiga menhir ini berukuran panjang sekitar $40 \mathrm{Cm}$ dan diameter sekitar $15 \mathrm{Cm}$. Di sekitar menhir terdapat sisa-sisa wadah sesaji dari bahan plastik.

Tinggalan pada masa klasik/ pengaruh budaya dan agama Hindu/ Buda, diantaranya:

a. Prasasti dibuat dari bahan batu andesit pada kedua permukaan di ratakan untuk tempat pemahatan tulisan. Menggunakan bahasa dan tulisan jawa kauna. Berdasarkan Prasasti Suci yang ditemukan tahun 1836 di daerah Bangil, Pasuruan. Prasasti ini dikeluarkan pada masa pemerintahan Pu Sindok di Jawa Timur pada tanggal 12 Suklapaksa, bulan Asuji, tahun 851 Saka, yang bertepatan dengan tanggal 18 September 929 Masehi. Isinya antara lain bahwa Pu Sindok memerintahkan agar rakyat Cunggrang yang termasuk wilayah Bawang, di bawah pemerintahan langsung dari Wahuta Tungkal, untuk menjadi sima (tanah perdikan) bagi pertapan di Pawitra (sekarang Gunung Penanggungan), dan memelihara pertapaan dan prasada, juga memperbaiki bangunan pancuran di Pawitra.

1 Rangkuti Nurhadi: Ringkasan Makalah yang disampaikan dalam rangka Mencari Harijadi Pasuruan, Jawa Timur Tahun 2003 di hadapan DPRD Pasuruan 
Keberadaan prasasti Suci di wilayah Bangil, Pasuruan dapat dijadikan patokan untuk menentukan saat pertama kali wilayah Pasuruan dihuni oleh masyarakat manusia dan dicatat dalam sumber tertulis.

b. Prasasti Tuhanaru bertanggal 15 Suklapaksa pada bulan Margasira tahun Saka 1245 atau tanggal 13 Desember 1323 Masehi, yang dikeluarkan oleh Sri Sundara-Pandya-Dewa-Adhi-Iswara Wikrama-Utungga Dewa (gelar raja Jayanagara, raja Majapahit). Prasasti ini menyebut Tanjungpura yang hampir selalu disebut bersama-sama Madhura (Madura sekarang). Diperkirakan Tanjungpura (sebagai salah satu dari 14 negara daerah Majapahit) terdapat di wilayah Pasuruan sekarang.

c. Prasasti Waringin Pitu yang bertanggal 15 Suklapaksa bulan Margasira tahun Saka 1369 sama dengan 22 November 1447. Isinya menyebutkan tentang 15 nama keluarga kerajaan Majapahit, yang mulai dari Sri Bhatara Prabhu, Wijayaparakramawardhana, dyah Kertawijaya sampai Bhattara ring Kalinggapura, Kamalawarnadewi, dyah Sudayita. Selain itu prasasti ini juga berisi tentang daftar para menteri senior, pimpinan administrasi pemerintahan, pengurus bagian hukum dan keagamaan, dan menyebutkan pendharmmaan Rajasa Kusumapura. Di Pasuruan mengalir Sungai Rajasa yang bermuara ke laut Jawa di Kecamatan Rajasa. Kemungkinan di daerah itu tempat pendharmaan Rajasa Kusumapura.

Selain tinggalan arkeologis berupa beberapa buah prasasti tersebut, terdapat tingalan monumental penting di lereng Gunung Arjuna yakni disebelah barat laut atau bagian sisi selatan wilayah Pasuruan, berupa candi-candi Makuitarama, candi Sepilar, candi Semar, candi Bagong, candi Batara Guru, candi Mintasraya, dan candi Wesi. Banyaknya banguna suci di wilayah tersebut, menandakan bahwa pada masa lalu (masa klasik) kurang lebih pada abad XI -- XIV Masehi Pasuruan merupakan daerah yang cukup penting, baik sebagai daerah permukiman (setlement) maupun keagamaan dengan banyaknya candi-candi yang tersebar.

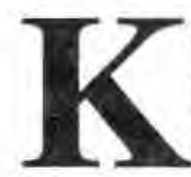

\section{ondisi Sosiologis dan Antropologis}

Berkaitan dengan konteks tersebut, Pasuruan sejak jaman dahulu merupakan sebuah komunitas manusia yang bersifat heterogen, terdiri dari etnis, Jawa Madura, Mandar, Bugis, Arab, Cina dan Eropa. Dalam sejarah perkembangan dan dinamika masyarakat Pasuruan telah menunjukan sikap keterbukaan dan mudah menerima pengaruh asing. Beberapa bukti sejarah yang mengidentifikasikan terjadinya kerukunan tersebut dengan adanya beberapa tempat suci yang tersebar, seperti; Masjid, Gereja, dan Kelenteng, serta beberapa Pura Hindu dan Budha di dataran tinggi Bromo. 
Bertemunya bermacam suku bangsa dan etnis-etnis yang bermukim di wilayah tersebut, mengakibatkan terjadinya percampuran beberapa unsur budaya. Unsur budaya yang bercampur didaerah ini salah satunya adalah dalam bidang kesenian, dan cerita rakyat. Kesenian tersebut kemudian terus berkembang dan masih dikenal dan disukai oleh masyarakat. Dari beberapa kesenian yang berkembang sebagian besar merupakan perpaduan antara seni tradisional dengan seni yang bernuansa islam. Beberapa seni, tradisi dan cerita rakyat yang terdapat di Pasuruan antara lain:

\section{Kesenian ${ }^{2}$ :}

a. Orkes Melayu, Kelompok orkes ini seluruhnya terdapat 59 kelompok yang tersebar di 18 kecamatan, dan terbanyak pada Kecamatan Pandaan, Nguling, Sukorejo, Rembang dan Gempol.

b. Ludruk, terdapat sembilan (9) kelompok yang tersebar ditujuh (7) kecamatan, diantaranya; Kecamatan Gempol, Lumbang, Nguling, Prigen, Purwosari, Sukorejo, dan Tosari.

c. Samroh, terdapat empat (4) kelompok yang tersebar di tiga (3) kecamatan; Wonorejo, Pasuruan, dan Pandaan.

d. Terbang Laro, terdapat tiga (3) kelompok yang tersebar di dua kecamatan; Purwodadi dan Purwosari.

e. Drama, terdapat dua kelompok di Kecamatan Sukorejo dan Lekok.

f. Karawitan, terdapat tujuh (7) kelompok yang tersebar di enam (6) kecamatan; Kecamatan Bangil, Gempol, Grati Pandaan, Purwodadi, dan Tutur.

g. Jaranan, terdapat 13 kelompok yang tersebar di delapan (8) kecamatan, antara lain; Kecamatan Grati, Kajayan Pasuruan, Pasrepan, Puspo, Nguling, Purwodadi, Tosari, dan Tutur.

h. Pencak Silat, terdapat dua puluh empat (24) kelompok yang tersebar di 17 kecamatan.

Beberapa kesenian yang bernuansa keagamaan (Islam) dan berkembang di dalam pondok-pondok pesantren dan kelompok etnis Cina, seperti:

a. Seni Hadra yang dikenal luas oleh masyarakat, seni ini merupakan perpaduan antara gerak tari dan nyanyian yang berisikan pujian-pujian kepasa Tuhan dan bernuansa Islam. Kesenian ini bergaya Timur Tengah dengan iringan musik terbanan yang ditarikan oleh pria dan wanita. Hadrah sering digunakan untuk mengiringi acara perkawinan.

b. Pada masyarakat etnis Cina di Pasuruan, akhir-akhir ini mulai berkembang tarian Barongsai yang di adakan di halaman Kelenteng Tjoe Tik Kiong (Tjoe $=$ Welas Asih, Tik= Kebajikan dan Kiong= Istana Suci). Berdiri sekitar tahun 1750- an, dan termasuk kelenteng tertua kedua di Pulau Jawa.

2 Sumber Departemen Pendidikan Dan Kebudayaan, Kantor Kabupaten Pasuruan 1998. 


\section{Tradisi}

Beberapa tradisi bernuansa islam yang masih dilestarikan oleh masyarakat Pasuruan hingga saat ini, diantaranya adalah:

a. Sakban, saban berasal dari ajaran islam yang mengandung arti pertengahan bulan ruwah, setiap setahun sekali. Tradisi ini terdapat di Kecamatan Pasuruan pada Sungai Gembong. Lama-kelamaan tradisi ini menjadi semacam pesta rakyat yang diadakan setahun sekali pada pertengahan bulan Ruwah. Tradisi ini lebih dikenal khususnya oleh mereka yang tinggal di daerah sekitar Kota Pasuruan.

b. Pesta rakyat Skilot, di selenggarakan oleh masyarakat Kecamatan Lekok. Bentuk pesta ini adalah untuk bersenang-senang sebelum masa tanam padi. Permainan ini berlokasi di sawah yang disiram dengan air sehingga berlumpur. Arena tersebut untuk berpacu dengan menggunakan alas dari papan kayu sebagai alas kaki kanan dan kiri, dilakukan berkelompok oleh dua atau tiga orang. Pada saat start biasanya terdiri dari 5 sampai 10 starter. Lomba jenis ini awal mulanya dari permainan anak yang berkembang menjadi permainan yang dapat dilakukan oleh semua kelompok umur.

c. Tradisi Larungan, dilakukan oleh suku Madura di daerah Kecamatan Lekok. Tradisi ini berupa pembuatan miniatur perahu lengkap dengan layarnya dan berwarna-warni, yang pada bagian tengahnya di isi muatan berupa hasil panen, dan jajan pasar yang kemudian di larung ketengah laut diiringi dengan doa dan kegembiraan para peserta baik tua maupun muda.

d. Tradisi Penetapan Sesepuh Desa, Tradisi ini cukup dikenal oleh masyarakat Kecamatan Grati. Dilakukan oleh para sesepuh, tokoh masyarakat dan perangkat Desa Ranu Klindungan, untuk melakukan pemilihan atau menetapkan seorang sesepuh desa.

\section{Cerita Rakyat/ Folklore}

Di wilayah Pasuruan terdapat cerita rakyat berupa legenda yang mengisahkan tentang asal-usul maupun kejadian yang berkaitan dengan sejarah lokasi/daerah yang terdapat di Pasuruan. Diantara cerita rakyat yang berkembang di Pasuruan ini adalah mengenai Ranu Grati, Winongan, Pemandian Banyu Biru, Kakek Bodo, serta Pedukuhan Surengpati dan Surengrono yang inti ceritanya sebagai berikut.

a. Riwayat Ranu Grati

Di wilayah Kecamatan Grati, yaitu di Desa Ranuklindungan terdapat sebuah ranu/danau yang disebut Ranu Grati. Menurut legenda, ranu ini dan lokasi sekitarnya berkaitan erat dengan tokoh Endang Sukarni yang merupakan putri seorang adipati wilayah Majapahit, Demang Klindungan, Ki Wongsopati, Kyai Syekh Begawan Nyampo, dan Baru Klinthing. Dalam legenda ini diceritakan bahwa Endang Sukarni dalam perjalanannya berkelana dan bertapa membisu sampailah di wilayah Kademangan Klindungan, dan akhimya 
dikawin oleh Ki Demang Klindungan. Akibat perkawinan ini melandalah wabah penyakit di desa tersebut. Berdasarkan saran Ki Wongsopati, akhirnya Endang Sukarni dibuang di Padukuhan Bawean. Selanjutnya Endang Sukarni dikawini oleh Kyai Syekh Begawan Nyampo dan melahirkan seorang anak yang berwujud seekor ular. Ular ini diberi nama Joko Baru dan terkenal dengan sebutan Baru Klinthing. Sementara keberadaan Ranu Grati tercipta oleh kesaktian Kyai Syekh Begawan Nyampo, yaitu melalui mata air yang terbentuk akibat pencabutan sebuah lidi yang ditancapkannya.

\section{b. Riwayat Winongan}

Dalam cerita ini disebutkan bahwa Winongan yang pada saat ini merupakan sebuah kecamatan, dulunya merupakan pusat pemerintahan Kadipaten Pasuruan. Sebagai bupati pada masa itu adalah Pangeran Murdangkoro yang berasal dari Kerajaan Mataram. Adipati ini mempunyai pembantu kepercayaan bernama Pangeran Ngangrangkusumo yang terkenal sebagai empu pembuat senjata/pusaka, dan menggantikan kedudukan Adipati setelah Pangeran Murdangkoro meninggal. Pada masa pemerintahan Pangeran Ngangrangkusumo muncullah tokoh bernama Joko Unthuk yang sangat sakti. Joko Unthuk pada masa bayinya pernah dibuang di kawah Gunung Semeru oleh orang tuanya, namun masih hidup dan muncul pada suatu mata air. Oleh Pangeran Ngangrangkusumo, Joko Unthuk diangkat sebagai Empu Kadipaten sebagai balas jasa setelah Joko Unthuk dapat mengalahkan seekor kerbau yang mengamuk di alun-alun Kadipaten.

\section{c. Asal Usul Pemandian Banyu Biru}

Menurut cerita, keberadaan pemandian Banyu Biru terkait dengan tokoh Kebut dan Tombro. Kedua tokoh ini merupakan prajurit Majapahit yang melarikan diri akibat desakan agama Islam. Dalam pelariannya sampailah ke wilayah yang saat ini masuk dalam Desa Sumberejo, Kecamatan Winingan, Pasuruan. Di lokasi ini Kebut mengembangkan keahliannya di bidang pande besi, sedangkan Tombro mengembangnkan pertanian. Melalui kerbau peliharaannya, Tombro menemukan sebuah kolam yang airnya sangat jernih hingga berwarna biru. Dalam perkembangannya kemudian dikenal sebagai Banyu Biru, namun ada yang menyebutnya sebagai Telaga Wilis. Makam kedua tokoh dalam cerita ini terdapat di sekitar pemandian Banyu Biru tersebut.

\section{d. Kakek Bodo}

Cerita ini berkaitan dengan tokob pelarian prajurit Mataram, khususnya Dwi Asmoro Diponegoro. Prajurit ini melarikan diri akibat kekalahannya dalam peperangan melawan Belanda. Dalam pelariannya sampailah ke hutan Gunung 
Limas, di lereng Utara Gunung Welirang. Atas perjuangannya membuka daerah ini, banyaklah penduduk yang tinggal di daerah tersebut.

Pada suatu waktu terdapat wabah penyakit yang menyerang penduduk di daerah itu, namun berkat pertolongan Dwi Asmoro Diponegoro, wabah penyakit tersebut dapat diusirnya. Akibat keberhasilan pertolongannya, oleh masyarakat setempat Dwi Asmoro Diponegoro akan diangkat sebagai sesepuh daerah. Namun Dwi Asmoro Diponegoro tidak mau menerima anugerah tersebut, dan malahan pergi untuk bertapa. Penolakan anugerah tersebut dianggap oleh masyarakat setempat sebagai tindakan yang bodo (Ind: bodoh), sehingga kemudian Dwi Asmoro Diponegoro terkenal disebut sebagai Kakek Bodo.

\section{e. Asal-usul Nama Pedukuhan Surengpati dan Surengrono}

Pedukuhan Surengpati dan Surengrono terletak di wilayah Desa Sukorejo, Kecamatan Sukorejo, Kabupaten Pasuruan. Menurut cerita nama Dukuh Surengpati berasal dari nama seorang Prajurit Arya Penangsang yang melarikan diri akibat kejaran prajurit Mataram yang makamnya ditemukan di dukuh tersebut.

Semula makam yang tidak diketahui identitasnya ini, konon ditemukan oleh Mbah Satariyah saat menebang pohon. Dan menurut cantrik/pengikut Surengpati yang masih hidup ketika makam tersebut ditemukan diketahuilah bahwa makam tersebut adalah makam Surengpati. Sementara Dukuh Surengrono berasal dari tulisan Surengrono yang terdapat di atas batu besar yang ada di daerah tersebut. Menurut cerita (dari cantrik Surengpati), batu besar ini merupakan tempat pertemuan, sarasehan, dan semedi para pengikut Surengpati.

Selain seni dan tradisi yang berkembang pada masyarakat Pasuruan di daerah pesisir atau dataran rendah, pada masyarakat yang tinggal di daerah dataran tinggi Gunung Bromo, yakni suku Tengger memiliki sosial budaya dan agama yang khas dan sangat menarik. Dalam kehidupan sehari-hari masyarakat Tengger memiliki beberapa tradisi yang sangat dikenal dalam dunia budaya dan pariwisata.

Masyarakat Tengger terdapat di Pegunungan Tengger dan Bromo, wilayahnya meliputi empat kabupaten, yaitu Kabupaten Pasuruan dan Kabupaten Probolinggo, di bagian utara, serta Kabupaten Malang dan Kabupaten Lumajang di bagian selatan. Masyarakat Tengger di Kabupaten Pasuruan terdapat di wilayah Kecamatan Puspa, Kecamatan Tosari dan Kecamatan Tutur. Di Kecamatan Puspa terdapat desa Tengger asli, yaitu di Dusun Keduwung, sedangkan di Kecamatan Tosari terdapat di Desa Tosari. 
Masyarakat Tengger merupakan bagian dari suku Jawa yang memiliki sejarah yang berhubungan dengan Kerajaan Singhasari dan Majapahit. Menurut legenda setempat, desa-desa Tengger dirintis oleh Prabu Brawijaya V dan Ki Dada Putih yang datang dari Singhasari, yang pada akhirnya mendirikan 12 desa Tengger yang kuna. Desa tertua Tengger terdapat di Keduwung, yang kini masuk Kecamatan Puspa, sedangkan desa yang termuda adalah Desa Tosari sekarang, yang terdapat di Kecamatan Tosari. Masyarakat Tengger sekarang menganut agama Hindu, Buddha dan Islam. Pada umumnya mereka hidup bertani dengan mengolah lahan pada lereng-lereng bukit yang cukup terjal.

Masyarakat Tengger memiliki upacara-upacara ritual, yang menggambarkan perpaduan antara kepercayaan asli nenek moyang dan agama Hindu. Upacara Kasodo, Karo, Unan-unan dan Entas-entas merupakan upacara-upacara yang diikuti oleh seluruh masyarakat Tengger, baik yang beragama Hindu dan Buddha, maupun yang beragama Islam.

Hal yang penting untuk dicatat dalam hal ini adalah sifat kegotongroyongan dan toleransi agama yang tinggi pada masyarakat Tengger. Fenomena tersebut menggambarkan bahwa: masyarakat Pasuruan baik yang hidup di daerah pesisir/ pantai yang relatif terbuka oleh pengaruh budaya, akibat terjadi kontak-kontak dagang, terutama dimulai pada sekitar abad XVI M dengan masuknya pedagang Arab, Cina yang kemudian disusul oleh orang-orang Belanda. Tanpa dilandasi oleh sifat keterbukaan, mustahil mereka mau menerima kedatangan suku dan bahkan bangsa asing masuk kewilayah tersebut. Sebaliknya bagi masyarakat Pasuruan yang tinggal di daerah sebelah selatan merupakan daerah pegunungan masyarakat (Tengger), secara geografis merupakan daerah yang tertutup karena medan yang berat tetapi justeru memiliki adat istiadat dan tradisi yang masih dipertahankan samapai kini. Mereka-pun mau menerima orang luar untuk masuk ke wilayahnya, dengan prinsip untuk hidup secara damai berdampingan dalam membangun kehidupan dan masa depan mereka.

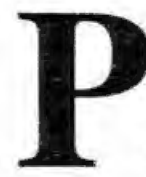

enutup

Sumbangan arkeologis dalam usaha mengkaji sumber-sumber data tertua, dalam usaha suatu pemerintah daerah untuk mengetahui kapan sebuah wilayah/ kabupaten bersangkutan berdiri atau keberadaannya. Dengan mengetahui sumber data arkeologis dan bukti-bukti yang masih ada tentunya merupakan bukti otentik tentang peranan penting suatu wilayah tersebut pada masa-masa lalu. Data arkeologis sekaligus juga membuktikan bahwa suatu daerah tersebut telah menjadi daerah penting dengan adanya hunian-hunian/ permukiman yang biasanya ditandai adanya tempat-tempat suci dan situs-situs arkeologis. 
Data dan informasi berupa seni, tradisi dan cerita rakyat (folklor) merupakan acuan pendukung, karena biasanya di situ ada obyek arkeologisnya, biasanya juga ada infomasi berupa kisah-kisah, riwayat-riwayat para tokoh tertentu yang berhubungan dengan situs. Informasi tersebut sangat penting guna menambah argumentatif yang akan dikemukan dalam forum seminar-seminar harijadi dengan aparatur Pemerintah daerah dan para anggota dewan. Data berupa tutur, seni dan tradisi tersebut juga dapat ditulis sebagai muatan sejarah lokal bagi daerah yang bersangkutan.

Makna sebuah harijadi suatu daerah tertentu sebenarnya mengandung pemahaman yang sangat kompleks dan hakiki bagi pemerintah daerah dan masyarakatnya. Melalui kajian sumberdaya budaya yang terdapat di Pasuruan, baik dari kebudayaan material maupun non material (perilaku budaya), dapat dikenali beberapa ciri utama, yang menjadi identitas budaya Pasuruan. Sejarah dan tradisi budaya menunjukkan bahwa dari masa ke masa masyarakat Pasuruan merupakan masyarakat yang heterogen, baik etnik, ras, agama, profesi dan status sosial,. Masyarakat yang heterogen ini memiliki toleransi yang tinggi dalam menyikapi perbedaan-perbedaan yang muncul. Selain itu kehidupan beragama sangat harmonis, terutama pada masyarakat tradisional di Pasuruan. Dalam masa yang tidak menentu in, hendaknya para arkeolog dapat mampu untuk melakukan pendektan-pendekatan dengan pemerintah-pemerintah daerah untuk mengkaji dengan melakukan penelitian secara obyektif suatu wilayah/ daerah tertentu berdasarkan kajian data arkeologis dan dibantu oleh data lain yang bermanfaat sebagai pendukung data arkeologis yang ada. Quo vadis Arkeologi.

INFORMAN/ NARASUMBER

1. Bambang Oedajadi (Yayasan Untung Surapati, Pasuruan)

2. Drs. Moch. Nasir (Dinas Pendidikan dan Kebudayaan Kab. Pasuruan)

3. Drs. H. Untung Sutjahjo NS. (P3GI di Pasuruan)

4. Poerwo Soedibjo (Jl. Taman Indrakila, Pasuruan)

5. Drs. Indra Sukma BS (Balibangda Kab. Pasuruan) 


\section{KEPUSTAKAAN}

Karto Atmodjo, MM. Sukarto, 1996. Menelusuri Harijadi Jember Berdasarkan Data Prasasti Congapan. (Paper). Dalam rangka mencari harijadi Jember, Jawa Timur.

Koentjaraningrat, 1974. Beberapa Pokok Antropologi Sosial, Penerbit PT Dian Rakyat, Jakarta.

Leach, Maria (editor), 1949. Standar Dictionary Of Folklore, Mythology, And Legend. New York, Funk \& Wagnalls Company.

Rangkuti, Nurhadi, 2003. Makalah yang disampaikan dalam rangka Mencari Harijadi Pasuruan, Jawa Timur. 